\title{
Application of Mathcad environment in the general course of physics at preparation of experts of engineering specialties
}

\author{
Dydenchuk A. F.", Khalanchuk L. V. \\ Dmytro Motornyi Tavria State Agrotechnological University, Melitopol, Ukraine
}

Received: $28.08 .2020 \quad$ Accepted: 18.11 .2020

\begin{abstract}
The article discusses a methodological approach to solving problems when studying the topic «Harmonic oscillations» in the course of general physics using the Mathcad software package when training specialists in engineering specialties. In the course of the research, the scientific literature was theoretically analyzed, the experience of using teaching methods was studied. The methodological basis of the research is an integrated approach that combines traditional forms of teaching and learning using the Mathcad software package. An illustrative principle of teaching and presenting information is given on the example of two tasks to demonstrate the capabilities of the Mathcad software package in the classroom in higher education institutions. The considered examples are given in general form without numerical calculations, when supplemented with numerical values and changing the initial conditions, it is possible to increase the number of possible tasks based on the given templates. The methodical approach is introduced into the educational process. As a result of observation of the lessons, the results obtained were summarized and systematized. It is proposed to supplement the solution of these problems with the help of computer modeling with an analytical solution for comparing and checking the results obtained. The introduction of the proposed methodological approach into the educational process demonstrates an increase in students' motivation to master the discipline as a whole; the acquisition by students of the skills of using computer programs to solve professionally oriented problems; presentation of educational material in a visual form; saving study time, etc. Solving problems of applied content encourages students to independently establish intersubject connections in natural-mathematical and special disciplines at different levels and contributes to the transfer of knowledge from one field of science to another. The approach used encourages students to independently model oscillating processes to study the operation of various devices and structures. Using the considered methodology for solving the above examples in the Mathcad environment, students can master not only mathematical competencies, but also additionally related to information processing; to gain the skills of analysis and search for optimal solutions, which is inherent in engineering specialties.
\end{abstract}

Key words: software packages, Mathcad environment, oscillating processes, problems of applied content.

\section{Застосування середовища Mathcad у загальному курсі фрізики при підготовці фахівців інженерних спеціальностей}

\author{
Дяденчук А. Ф., Халанчук Л. В. \\ Таврійський державний агротехнологічний університет імені Дмитра Моторного, Мелітополь, Україна
}

\begin{abstract}
Анотація. У статті розглянуто методичний підхід до розв'язання задач під час вивчення теми «Гармонічні коливання» у курсі загальної фрізики із застосуванням програмного пакету Mathcad при підготовці фрахівців інженерних спеціальностей. У процесі дослідження теоретично проаналізовано наукову літературу, вивчено досвід використання методик навчання. Методологічною основою дослідження $є$ комплексний підхід, що поєднує традиційні форми навчання та навчання з використанням програмного пакету Mathcad. Наведено наочний принцип навчання і подачі інформації на прикладі двох задач для демонстрації можливостей програмного пакету Mathcad на заняттях у закладах вищої освіти. Розглянуті приклади задані у загальному вигляді без числових розрахунків, при доповнені їх цифровими значеннями та змінюючи початкові умови можна збільшити кількість можливих завдань на базі наведених шаблонів. Методичний підхід впроваджено у навчальний процес. У результаті спостереження за заняттями узагальнено й систематизовано отримані результати. Розв'язування наведених завдань за допомогою комп'ютерного моделювання пропонується
\end{abstract}

Corresponding Author: Dyadenchuk Alena Fedorivna. Tel. +38(066)828-85-19. E-mail: alena.dyadenchuk@tsatu.edu.ua. Dmytro Motornyi Tavria State Agrotechnological University, B. Khmelnytskoho Ave., 18, Melitopol, Ukraine, 72312.

Відповідальний автор: Дяденчук Альона Федорівна. +38(066)828-85-19. E-mail: alena.dyadenchuk@tsatu.edu.ua. Таврійський державний агротехнологічний університет імені Дмитра Моторного, пр. Б. Хмельницького, 18, Мелітополь, Україна, 72312. 
доповнювати аналітичним розв'язком задля порівняння та перевірки отриманих результатів. Впровадження у навчальний процес запропонованого методичного підходу демонструє підвищення мотивації студентів до освоєння дисципліни в цілому; набуття студентами навичок використання комп'ютерних програм для розв'язування професійно-орієнтованих задач; представлення навчального матеріалу в наочному вигляді; економія навчального часу тощо. Розв'язування задач прикладного змісту спонукає студентів до самостійного встановлення міжпредметних зв'язків природничо-математичних і спеціальних дисциплін на різних рівнях та сприяє перенесенню знань із однієї галузі науки в іншу. Використаний підхід спонукає студентів самостійно моделювати коливні процеси для дослідження роботи різних пристроїв та конструкцій. Використовуючи розглянуту методику розв'язання наведених прикладів у середовищі Mathcad, студенти можуть освоїти не тільки математичні компетенції, а й додатково, пов'язані з обробкою інформації, отримати навички аналізу та пошуку оптимальних рішень, що притаманне інженерним спеціальностям.

Ключові слова: програмні пакети, середовище Mathcad, коливні процеси, задачі прикладного змісту.

\title{
Применение среды Mathcad в общем курсе физики при подготовке специалистов инженерных специальностей
}

\author{
Дяденчук А. Ф., Халанчук Л. В. \\ Таврический государственный агротехнологический университет имени Дмитрия Моторного, Мелитополь, Украина
}

\begin{abstract}
Аннотация. В статье рассмотрен методический подход к решению задач при изучении темы «Гармонические колебания» в курсе общей фризики с применением программного пакета Mathcad при подготовке специалистов инженерных специальностей. В процессе исследования теоретически проанализирована научная литература, изучен опыт использования методик обучения. Методологической основой исследования является комплексный подход, сочетающий традиционные формы обучения и обучения с использованием программного пакета Mathcad. Приведен наглядный принцип обучения и подачи инсоормации на примере двух задач для демонстрации возможностей программного пакета Mathcad на занятиях в учреждениях высшего образования. Рассмотренные примеры заданы в общем виде без числовых расчетов, при дополнении их цифровыми значениями и изменяя начальные условия можно увеличить количество возможных задач на базе приведенных шаблонов. Методический подход внедрен в учебный процесс. В результате наблюдения за занятиями обобщены и систематизированы полученные результаты. Решение указанных задач с помощью компьютерного моделирования предлагается дополнять аналитическим решением для сравнения и проверки полученных результатов. Внедрение в учебный процесс предложенного методического подхода демонстрирует повышение мотивации студентов к освоению дисциплины в целом; приобретение студентами навыков использования компьютерных программ для решения профессионально-ориентированных задач; представления учебного материала в наглядном виде; экономии учебного времени и т. п. Решение задач прикладного содержания побуждает студентов к самостоятельной установки межпредметных связей естественно-математических и специальных дисциплин на разных уровнях и способствует переносу знаний из одной области науки в другую. Использованный подход побуждает студентов самостоятельно моделировать колеблющиеся процессы для исследования работы различных устройств и конструкций. Используя рассмотренную методику решения приведенных примеров в среде Mathcad, студенты могут освоить не только математические компетенции, но и дополнительно, связанные с обработкой информации; получить навыки анализа и поиска оптимальных решений, что присуще инженерным специальностям.
\end{abstract}

Ключевые слова: программные пакеты, среда Mathcad, колеблющиеся процессы, задачи прикладного содержания.

\section{Bcmyn}

При підготовці висококваліфікованих фахівців інженерних спеціальностей чільне місце посідає здатність розв'язувати спеціалізовані практичні задачі, що мають надзвичайно широке прикладне значення в найрізноманітніших галузях науки і практичної діяльності людини. Розв'язання професійноорієнтованих задач нерідко викликає труднощі у студентів, оскільки потребує застосування складного математичного апарату та представляється у вигляді громіздких фрормул. До того ж найчастіше відповідь $€$ наближеною, а не аналітичною. При використанні математичного апарату удосконалюються навички використання математичних методів, однак втрачається практична значущість завдання та розв'язку.

Наразі існують різні методики моделювання та створена велика кількість програмних пакетів придатних для розв'язування прикладних задач. Питаннями впровадження комп'ютерного моделювання у навчальний процес ЗВО займалися Гриценко В. Г. [1], Семещук І. Л. [2], Сосницька Н. Л. [3], Атаманчук 
П. С. [3], Заболотний В. Ф. [4] та інші. Виділяються такі програмні пакети як Mathcad, Maple, Maxima, GRAN, електронні таблиці Microsoft Excel тощо [5-9]. Однак перевага надається саме Mathcad, оскільки він, крім візуалізації процесів, дозволяє розв'язувати вихідні завдання в галузі математичної фрізики за допомогою чисельних методів [10-11]. У роботах [12-13] нами представлено результати розробки методичного підходу розв'язання фізичних задач із основами диференціального та інтегрального числення шляхом моделювання в програмі Mathcad. У результаті запропонованого підходу студенти легше сприймають зміст навчального матеріалу і можливості застосування математичного пакету програм Mathcad для розв'язання прикладних задач та побудови найпростіших математичних моделей фізичних процесів [14-16]. Запропонований математичний пакет дозволяє вирішувати завдання саме прикладної природи, коли необхідно отримати результат без поглиблення в математичну суть завдання [17]. Комп'ютерне моделювання $є$ одним з ефективних методів вивчення фізичних систем, в тому числі коливальних процесів, неконтрольоване виникнення і поширення яких може призвести до виведення 3 ладу приладів та конструкцій електроенергетичної, будівельної, радіотехніки тощо [18-19].

Вищезазначене сприяє подальшому пошуку нових методик навчання та впровадженню нових підходів викладання професійно-орієнтованих дисциплін.

Метою cmammi є розробка методичного підходу до розв'язання задач під час вивчення теми «Гармонічні коливання» у курсі загальної фізики із застосуванням програмного пакету Mathcad при підготовці фахівців інженерних спеціальностей з метою розширення бази отриманих знань, підвищення доступності знань за рахунок наочності та більш глибокого розуміння окремих питань курсу.

\section{II Матеріал і методи дослідження}

У процесі дослідження використано наступні методи: теоретичний аналіз наукової літератури, вивчення досвіду використання методик навчання та інноваційних підходів на заняттях фізики; спостереження за заняттями та їх аналіз; педагогічний експеримент; узагальнення й систематизація отриманих результатів. Методологічною основою дослідження $є$ комплексний підхід, що поєднує традиційні форми навчання та навчання з використанням програмного пакету Mathcad.

Процес моделювання під час вивчення теми «Гармонічні коливання» було виконано за наступним алгоритмом:

1. Аналіз та запис умови задачі. На даному етапі відбувається детальний аналіз умови задачі та визначення вхідних і невідомих даних. При цьому слід визначити до якого типу задач про гармонічний коливальний рух необхідно віднести пропоновану задачу: до задач на кінематику коливального руху чи до задач на динаміку коливального руху. Початкова фаза $\varphi_{0}$ або задається в умові задачі, або знаходиться з початкових умов.

2. Визначення ключових формул необхідних для розв'язання задачі. Задачі на кінематику коливального руху вимагають застосування рівняння гармонічного коливання:

$$
x(t)=A \sin \left(\omega_{0} t+\varphi_{0}\right) \text { або } x(t)=A \cos \left(\omega_{0} t+\varphi_{0}\right) .
$$

Швидкість і прискорення матеріальної точки, що здійснює гармонічні коливання, описують закони зміни швидкості і прискорення, які знаходять диференціюванням за часом вищезазначеного рівняння.

У задачах на динаміку коливального руху розглядається сума сил, що дорівнює квазіпружній силі, яка змінюється за законом

$$
F=-k x,
$$

де $k$ - коефіцієнт квазіпружної сили, що залежить від циклічної частоти:

$$
k=m \omega_{0}^{2} .
$$

Методи розв'язування задач на електромагнітні коливання подібні методам розв'язування задач на механічні коливання. Сила струму в коливальному контурі при вимушених коливаннях знаходиться диференціюванням закону, що описує власні коливання заряду на обкладинках конденсатора:

$$
q(t)=q_{\max } \cos \left(\omega_{0} t+\varphi_{0}\right),
$$

де $q_{\text {max }}$ - амплітудне значення заряду на конденсаторі.

Таким чином, даний етап вимагає запису другого закону Ньютона для конкретного виду коливального руху у вигляді диференціального рівняння. 


\section{3. Аналітичний розв'язок задачі.}

4. Завдання початкових умов і вихідних даних фрізичної системи в середовищі Mathcad. Початкові умови зручно подавати у вигляді матриці. Задаємо значення вхідним параметрам, враховуючи використання знаку присвоєння «:=» 3 панелі інструментів «Обчислення» або «Калькулятор». Для обчислення похідних фрункції використовується панель інструментів «Математичний аналіз» і знак « $\rightarrow$ аналітичного обчислення 3 панелі «Обчислення». Знаходимо параметри диференціального рівняння стандартної форми. Приклади цього етапу наведено на рис. 1 та рис. 5.

5. Організація обчислювальних циклів. На даному етапі записуються ітераційні розрахункові формули. Для їх виконання використовується панель інструментів «Програмування».

6. Отримання розв'язку диференціального рівняння в середовищі Mathcad у вигляді графіка. Щоб побудувати графік функції, використовується панель інструментів «Графік». Вигляд графіка можна змінити, якщо натиснути праву кнопку миші й обрати потрібний варіант (властивості, формат або інше). Приклади побудованих графіків наведено на рис. 2-4 та рис. 7.

\section{III Результати}

Для наочної демонстрації можливостей програмного пакету Mathcad на заняттях із курсу загальної фізики пропонується розглянути нижченаведені приклади з теми «Гармонічні коливання».

Приклад 1. Розглянемо гармонічні коливання, що описуються законом:

$$
s=A \sin \left(\omega_{0} t+\varphi_{0}\right)
$$

де $s$ - зміщення тіла (точки) від положення рівноваги, $A$ - амплітуда, $\omega_{0}=\frac{2 \pi}{T}$ - циклічна частота, $T$ період, $\varphi_{0}-$ початкова фаза [20].

Швидкість $v$ коливань тіла (точки) обчислюється як похідна від його зміщення:

$$
v=\frac{d s}{d t}=\omega_{0} \cdot \operatorname{Acos}\left(\omega_{0} t+\varphi_{0}\right) .
$$

3 рівняння (2) випливає, що швидкість коливання змінюеться з часом. Отже, коливальний рух відбувається з прискоренням:

$$
a=\frac{d^{2} s}{d t^{2}}=\frac{d v}{d t}=-\omega_{0}^{2} A \sin \left(\omega_{0} t+\varphi_{0}\right)=-\omega_{0}^{2} A \cdot s
$$

Реалізація лістингу прикладу 1 для значень вхідних параметрів $\varphi_{0}=0, A=2, \omega_{0}=2$ наведена на рисунку 1.

В результаті автоматичного розрахунку отримані графіки залежності зміщення, швидкості та прискорення від часу при $\varphi_{0}=0, A=1, \omega_{0}=1$ (рис. 2), $\varphi_{0}=0, A=2, \omega_{0}=2$ (рис. 3).

При зведених множниках (рівні 1) маємо однакову амплітуду зміщення, швидкості та прискорення, що демонструє рис. 2. Проте яскравішим є приклад залежності, коли множники не зведені (рис. 3).

$$
\begin{aligned}
\text { A }: & =2 \\
\varphi 0 & :=0 \\
\omega 0 & :=2 \\
s(t) & :=A \cdot \sin (\omega 0 \cdot t+\varphi 0) \\
v(t) & :=\frac{d}{d t} s(t) \rightarrow 4 \cdot \cos (2 \cdot t) \\
\mathrm{a}(\mathrm{t}) & :=\frac{\mathrm{d}}{\mathrm{dt}} \mathrm{v}(\mathrm{t}) \rightarrow-8 \cdot \sin (2 \cdot \mathrm{t})
\end{aligned}
$$

Рис. 1. Лістинг розрахунку для прикладу 1, реалізований у пакеті MathCad 


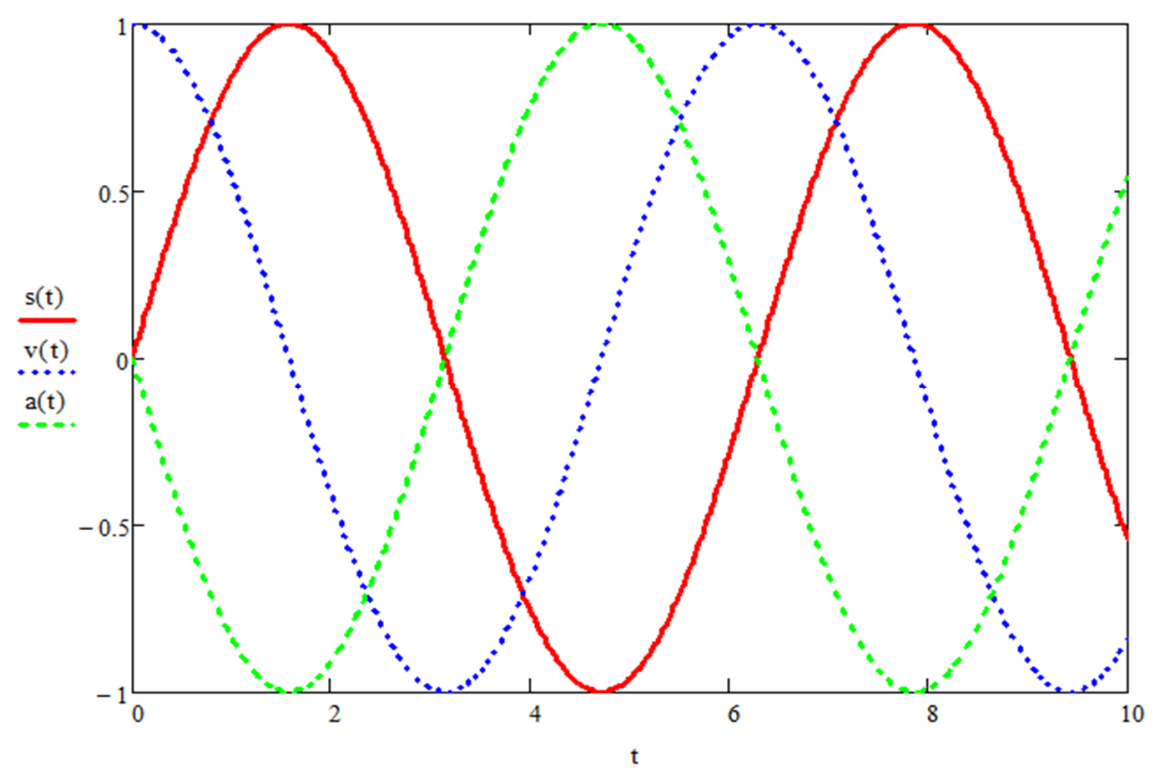

Рис. 2. Графріки залежності зміщення, швидкості та прискорення від часу при $\varphi_{0}=0, A=1, \omega_{0}=1$

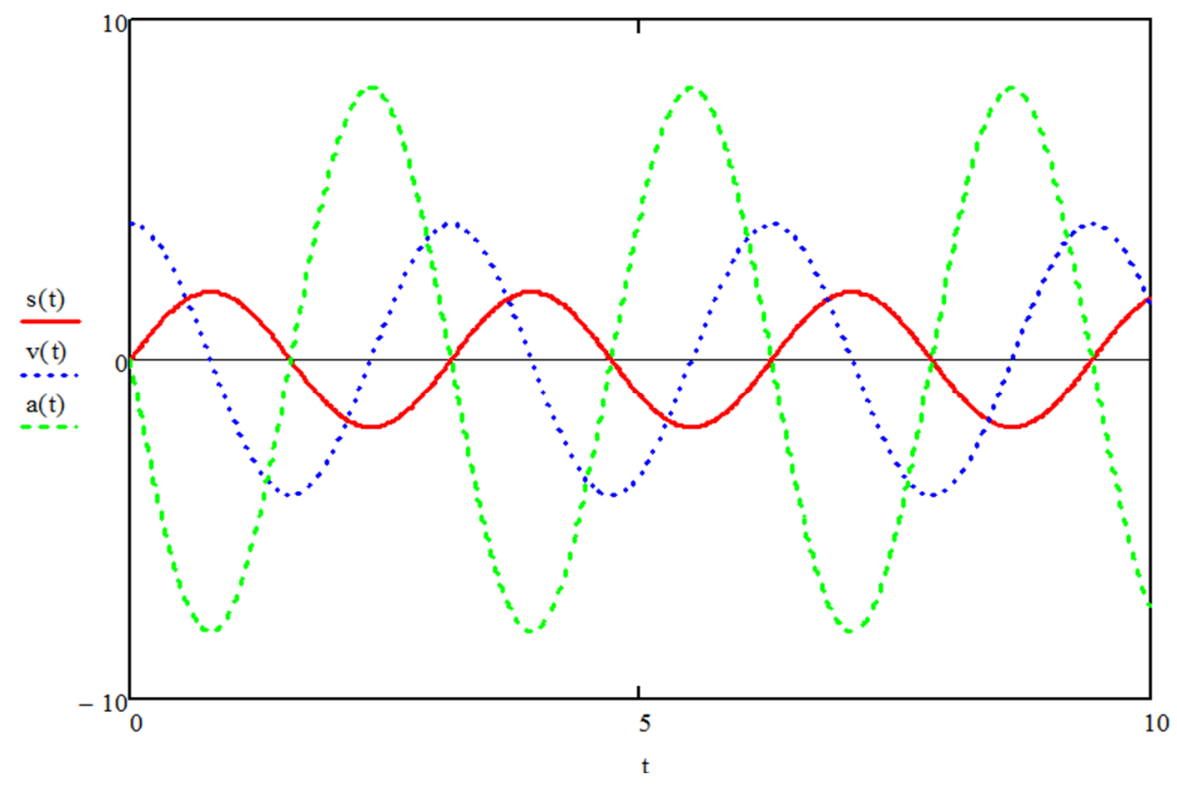

Рис. 3. Графріки залежності зміщення, швидкості та прискорення від часу при $\varphi_{0}=0, A=2, \omega_{0}=2$

Коли на тіло діє лише сила пружності з коесіцієнтом жорсткості $k$, тоді згідно другого закону Ньютона одержимо:

$$
m \frac{d^{2} s}{d t^{2}}+k \cdot s=0
$$

Позначимо $\omega_{0}^{2}=\frac{k}{m}$, тоді отримаємо диференціальне рівняння гармонічного коливання:

$$
\frac{d^{2} s}{d t^{2}}+\omega_{0}^{2} \cdot s=0
$$

Оскільки всередині коливної системи завжди присутня також сила тертя, то гармонічні коливання будуть затухати і з часом зовсім зникнуть. При невеликих швидкостях руху можна вважати, що сила тертя пропорційна швидкості руху тіла з коефіцієнтом опору середовища $r$.

Позначивши $\frac{r}{m}=2 \beta$, де $\beta$ - коефіцієнт затухання, отримаємо диференціальне рівняння затухаючих коливань: 


$$
\frac{d^{2} s}{d t^{2}}+2 \beta \frac{d s}{d t}+\omega_{0}^{2} \cdot s=0
$$

розв'язком якого є фуннція,

$$
s=A_{0} e^{-\beta t} \sin \left(\omega t+\varphi_{0}\right)
$$

де

$$
\omega=\sqrt{\omega_{0}^{2}-\beta^{2}} \text {. }
$$

Графрічно залежність $s(t)$ при $\varphi_{0}=0, A_{0}=1, \omega_{0}=2, b=0.1$ показано на рис. 4 , де студенти наочно можуть побачити, що коливання є затухаючими.

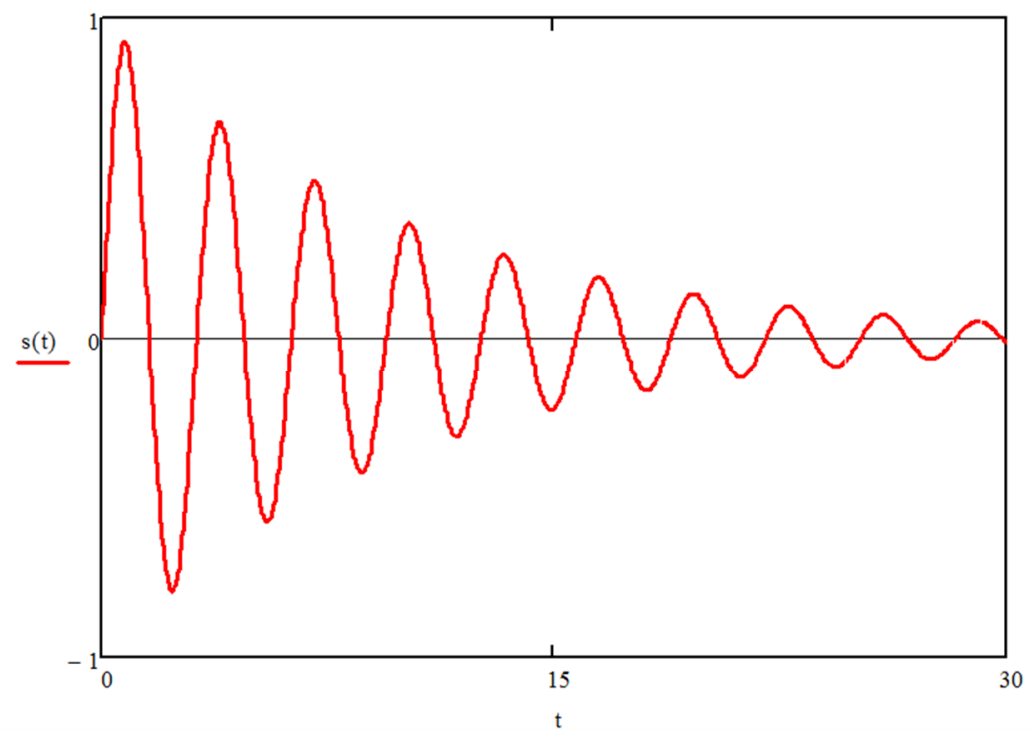

Рис. 4. Графік затухаючого коливання при $\varphi_{0}=0, A_{0}=1, \omega_{0}=2, b=0.1$

Приклад 2. Розглянемо електричну схему, що містить резистор $R$, котушку $L$ і конденсатор $C$. Використаємо диференціальні рівняння для моделювання заряду $Q$ на конденсаторі $C$ в пакеті програм Mathcad.

Запишемо диференціальне рівняння для напруги на всіх трьох компонентах, що в сумі повинно дорівнювати нулю:

$$
L \cdot \frac{d^{2}}{d \tau^{2}} Q(\tau)+R \cdot \frac{d}{d t} Q(\tau)+\frac{1}{C} \cdot Q(\tau)=0 .
$$

Запишемо диференціальне рівняння для миттєвого значення заряду в конденсаторі:

$$
\frac{d}{d t} Q(\tau)=0
$$

Задаємо значення заряду в нульовий момент часу:

$$
Q(0)=Q_{0}
$$

Задаємо значення вхідним параметрам і знаходимо параметри диференціального рівняння стандартної форми (рис. 5).

Зводимо диференціальне рівняння до стандартної фрорми:

$$
\frac{d^{2}}{d \tau^{2}} Q(\tau)+2 \cdot b \cdot \frac{d}{d t} Q(\tau)+a^{2} \cdot Q(\tau)=0 .
$$

Розв'язуємо рівняння (рис. 6) для всіх випадків $a$ та $b$ і будуємо графіки (рис. 7) двох можливих для $Q$ розв'язків. 


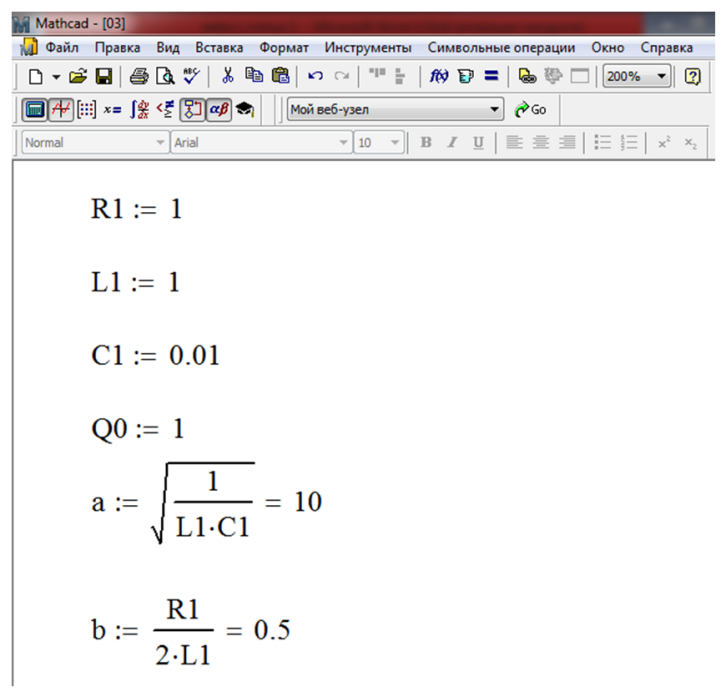

Рис. 5. Вхідні параметри та параметри рівняння стандартної форми.

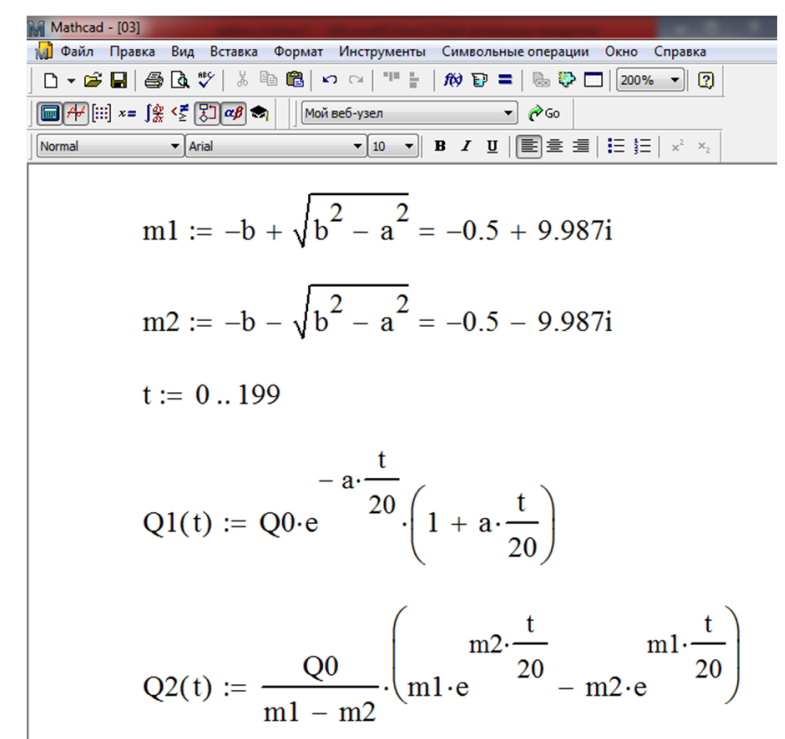

Рис. 6. Можливі розвязки диференціального рівняння

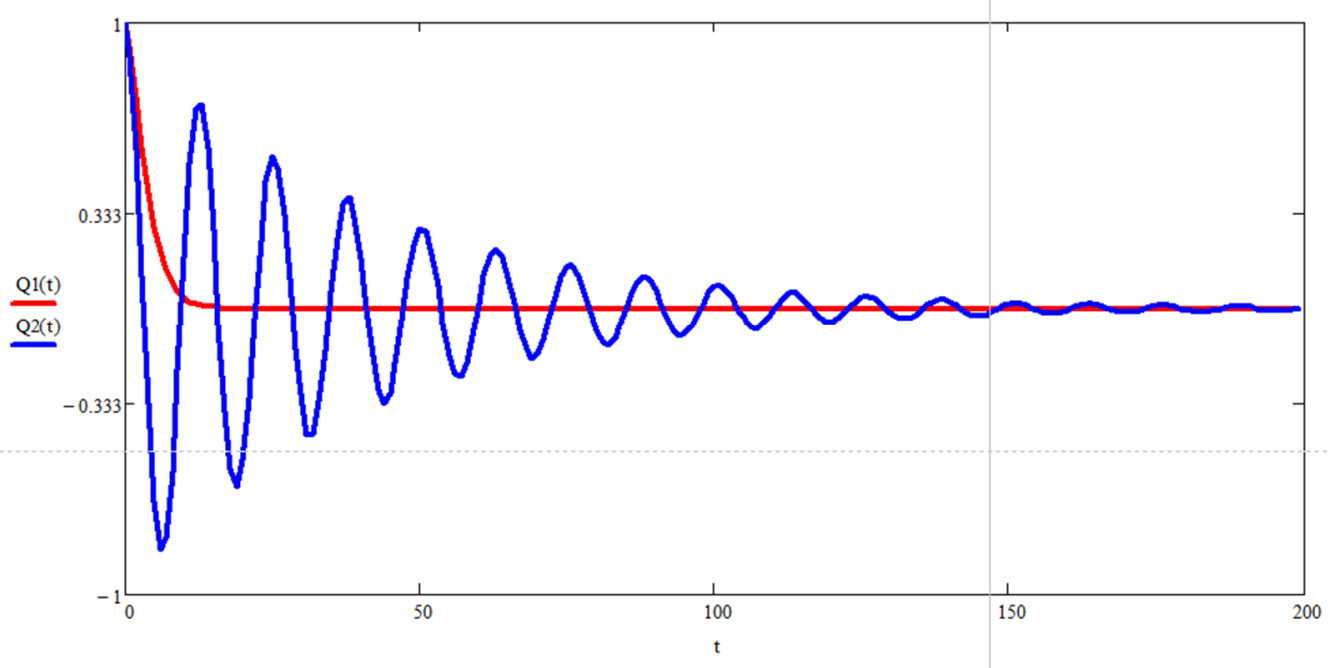

Рис. 7. Графріки двох можливих для $Q$ розв'язків 


\section{IV Обговорення}

У наведених прикладах розглянуто методику візуалізації гармонічних коливань у Mathcad. Моделювання коливальних процесів в Mathcad дає можливість більш наочно вивчити коливання будьякої природи. Оскільки розглянуті приклади задані у загальному вигляді без числових розрахунків, доповнюючи їх цифровими значеннями величин, змінюючи початкові умови та порівнюючи графіки розв'язків, можна значно збільшити кількість можливих завдань на базі наведених шаблонів.

Крім візуалізації наведених прикладів у Mathcad можна ввести і аналітично розв'язати вихідну задачу. До того ж чисельний розв'язок може бути корисним для порівняння та перевірки результатів розв'язання.

Впровадження у навчальний процес запропонованого методичного підходу продемонструвало підвищення мотивації студентів як до розв'язування задач з теми «Гармонічні коливання», так і до глибшого розуміння дисципліни в цілому. У результаті студенти не лише набувають навички використання програм для розв'язування фрізичних задач, але й демонструють підвищену зацікавленість в процесі навчання.

Візуалізація задач за допомогою програмних пакетів дозволяє як зекономити навчальний час, оскільки застосування пакету Mathcad значно зменшує час відведений на обчислення, так і представити навчальний матеріал зрозумілішим і доступнішим.

Розв'язування задач прикладного змісту спонукає студентів до самостійного встановлення міжпредметних зв'язків природничо-математичних і спеціальних дисциплін на різних рівнях та сприяє перенесенню знань із однієї галузі науки в іншу.

Використовуючи розглянуту методику розв'язання наведених прикладів у середовищі Mathcad, студенти можуть самостійно моделювати коливні процеси для дослідження роботи різних пристроїв та конструкцій, можуть освоїти не тільки математичні компетенції, а й додатково, пов'язані з обробкою інформації, отримати навички аналізу та пошуку оптимальних рішень, що притаманне інженерним спеціальностям.

\section{V Висновки}

У роботі наведено методичний підхід до розв'язання задач під час вивчення теми «Гармонічні коливання» у курсі загальної фрізики із застосуванням програмного пакету Mathcad при підготовці фахівців інженерних спеціальностей 3 метою розширення бази отриманих знань, підвищення доступності знань за рахунок наочності та більш глибокого розуміння окремих питань курсу.

Моделювання фізичних процесів під час проведення занять з фізики у середовищі Mathcad продемонструвало ряд переваг у порівнянні з традиційними методами навчання:

- підвищення мотивації студентів до освоєння дисципліни в цілому;

- набуття студентами навичок використання комп'ютерних програм для розв'язування професійно-орієнтованих задач;

- представлення навчального матеріалу в наочному вигляді; економія навчального часу тощо.

Запропонований підхід дозволить спростити розв'язання розрахункових завдань та побудови найпростіших математичних моделей фізичних процесів.

Використання розглянутої методики дозволяє зробити навчальний процес більш самостійним студенти можуть самостійно моделювати коливні процеси для дослідження роботи різних пристроїв та конструкцій, можуть освоїти не тільки математичні компетенції, а й додатково, пов'язані з обробкою інформації, отримати навички аналізу та пошуку оптимальних рішень, що притаманне інженерним спеціальностям.

\section{Бібліографічні посилання}

1. Гриценко В. Г. Нові інформаційні технології при вивченні статистичних закономірностей у процесі підготовки вчителів фізики : автореф. дис. ... канд. пед. наук : 13.00 .02 / Валерій Григорович Гриценко ; наук. кер. А. М. Гусак ; Національний педагогічний університет імені М. П. Драгоманова. Київ, 1999. 15 с. 
2. Тищук В.І., СемещукІ. Л., МислінчукВ. О.Вивчення властивостей електростатичного поля з використанням інформаційно-комунікаційних технологій / Науковий часопис НПУ імені М. П. Драгоманова. Серія 5 : Педагогічні науки : реалії та перспективи : зб. наук. праць. Київ : Вид-во НПУ імені М. П. Драгоманова, 2014. Вип. 48. С. 210-217.

3. АтаманчукП. С., Сосницька Н. Л. Основи впровадження інноваційних технологій навчання фізиці: навчальний посібник. Кам'янець-Подільський: Абетка-НОВА. (2007).

4. Заболотний В. Ф. Використання демонстраційних комп'ютерних моделей при навчанні методики вивчення хвильової оптики. Збірник наукових праць Кам'янець-Подільського національного університету імені Івана Огієнка. Серія педагогічна. 2006. Вип. 12. С. 110-113.

5. Дудик М., Решітник Ю., Коцик В. Використання інфформаційних технологій у самостійній роботі студентів фізичних спеціальностей з теоретичної фізики / Збірник наукових праць Уманського державного педагогічного університету. Умань, 2019. Вип. 4. С. 63-73.

6. СемещукІ.Л. Методичні особливості навчання розв'язування задач на знаходження екстремумів фізичних параметрів / Комп'ютерно-орієнтовні системи навчання : зб. наук. праць. Київ : НПУ ім. М. П. Драгоманова, 2003. Вип. 6. C. $260-268$.

7. Бардус І. О., Єфименко Ю. О. Моделювання фізичних процесів за допомогою системи комп'ютерної математики Maple. Теорія та практика навчання фізико-математичних та технологічних дисциплін : збірник. Бердянськ : БДПУ, 2011. C. 38-46.

8. Benker H. Mathematische Optimierung mit Computeralgebrasystemen: Einführung für Ingenieure, Naturwissenschafter und Wirtschaftswissenschaftler unter Anwendung von MATHEMATICA, MAPLE, MATHCAD, MATLAB und EXCEL. SpringerVerlag. 2013. $499 \mathrm{p}$.

9. Musina O., Putnik P., Koubaa M., Barba F. J., Greiner R., Granato D., Roohinejad S. Application of modern computer algebra systems in food formulations and development: a case study. Trends in Food Science \& Technology, 2017. Vol. 64, 48-59 p.

10. Solodov A., Ochkov V. Differential models: an introduction with Mathcad. Springer Science \& Business Media, 2005. 232 p.

11. Donnelly D. P. MathCAD for introductory physics. Addison-Wesley, 1992. $386 \mathrm{p}$.

12. Дяденчук А. Ф., ХаланчукЛ. В. Міжпредметні зв'язки фізики і математики при вивченні інтегрального числення / Розвиток сучасної науки та освіти: реалії, проблеми якості, інновації: матеріали Міжнародної науково-практичної інтернет-конференції (Мелітополь, 27-29 травня 2020 р.) Мелітополь: ТДАТУ, 2020. С. 102-107.

13. Дяденчук А. Ф., Халанчук Л. В. Візуалізація задач диференціального числення при підготовці студентів інженерних спеціальностей / Матеріали Всеукраїнської науково-практичної конфференції здобувачів вищої освіти і молодих вчених «Класичні та прикладні математичні проблеми у наукових дослідженнях здобувачів вищої освіти і молодих вчених: історичний та сучасний аспекти» (м. Харків, Україна, 9-10 квітня 2020 р.) Харків: ХНАДУ, 2020. С. 114-117.

14. Shalaby A. I., Zanganeh S. E. Teaching fluid mechanics using MathCAD / ASEE Annual Conference Proceedings. 2000. C. 5, p. 1.

15. Sosnickaya N., Morozov M., Khalanchuk L., Onyshchenko H. Modelling the Electromagnetic Processes and Phenomena in Quantum-Sized Systems in the Course of Physical and Mathematical Support of Master's Programs for the "Electric Power Engineering, Electrical Engineering and Electromechanics Specialty / IEEE International Conference on Modern Electrical and Energy Systems (MEES). Kremenchuk, 2019. Pp. 402-405.

16. Radu A., Grigore I., Barna V. Mathcad didactic tool for studying the elliptical oscillator. eLearning \& Software for Education, 2020. Vol. 2. Pp. 154-161.

17. Алексеев Р. Ю., Хоботова А. Ю. Моделирование колебательных процессов в среде Mathcad / Наука и перспективы, 2016. №2. URL: https://cyberleninka.ru/article/n/modelirovanie-kolebatelnyh-protsessov-v-srede-mathcad (дата обращения: 16.08.2020).

18. Mathcad 2000 User's Guide. Mathsoft, Inc., Cambridge, Massachusetts, 1999.

19. Boyd R. Tolerance Analysis of Electronic Circuits Using MATHCAD. Boca Raton: CRC Press, 1999. https://doi.org/10.1201/9781315215402

20. Вища математика: Інтегральне числення функції однієї змінної. Диференціальні рівняння : навчальний посібник для студентів технічних спеціальностей / Укл. Г. М. Кулик, О. І. Кушлик-Дивульська, Н. В. Степаненко, Н. П. Ярема. К. : HTYУ «КПI», 2016. $278 \mathrm{c}$.

\section{References}

1. Gritsenko, V. G. (1999). New information technologies in the study of statistical patterns in the process of training teachers of physics [Novi informatsiiny tekhnolohii pry vyvchenni statystychnyh zakonomirnostei u protsti pidhotovky vchyteliv fizyky]: dissertation abstract ... candidate of pedagogical sciences: 13.00.02 / Valery Grigorovich Gritsenko; Supervisor A. M. Gusak; M. P. Drahomanov National Pedagogical University. Kyiv. 15 p. [in Ukrainian]

2. Tyschuk, V. I., Semeschuk, I. L., Myslinchuk, V. O. (2014). Study of the properties of the electrostatic field using information and communication technologies [Vyvchennia vlastyvostei elektrostatychnoho polia z vykorystanniam informatsiinokomunikatstiinych tekhnolohii]. Scientific Journal of NPU named after M. P. Drahomanov. Series 5: Pedagogical sciences: realities and prospects: Collection of scientific works [Naukovyi chasopys NPU imeni M.P.Drahomanova. Seriia 5: Pedahohichni nauky: realii ta perspektyvy: zbirnyk naukovych pratst]. Kyiv: M. P. Drahomanov National Pedagogical University Publishing House. 48. 210-217. [in Ukrainian] 
3. Atamanchuk, P. S., Sosnitskaya, N. L. (2007). Fundamentals of implementation of innovative technologies for teaching physics: a textbook [Osnovy vprovadzhennia innovatstiinych technolohii navchannia fizytsti: navchalnyi posibnyk]. Kamenets-Podolsky: Alphabet-NEW.

4. Zabolotny, V. F. (2006). The use of demonstration computer models in teaching methods for studying wave optics [Vykorystannia demonstratstiinych kompiuternyh modelei pry navchanni metodyky vyvchennia hvyliovoi optyky]. Collection of scientific works of Kamyanets-Podilsky National University named after Ivan Ogienko. The series is pedagogical [Zbirnyk naukovych pratst Kamianetst-Podilskoho natstionalnoho universytetu imeni Ivana Ohienka. Seriia pedahohichna]. 12, 110113. [in Ukrainian]

5. Dudyk, M., Reshitnyk, Yu., Kotsyk, V. (2019). The use of information technology in the independent work of students of physical specialties in theoretical physics [Vykorystannia informatsiinykh tekhnolohii u samostiinii roboti studentiv fizychnykh specialnostei z teoretychnoi fizyky]. Collection of scientific works of Uman State Pedagogical University [Zbirnyk naukovych pratst Umanskoho derzhavnoho pedahohichnoho universytetu]. 4, 63-73. [in Ukrainian]

6. Semeshchuk, I. L. (2003). Methodical features of learning to solve problems to find extremums of physical parameters [Metodychni osoblyvosti navchannia rozv'iazuvannia zadach na znakhodzhennia ekstremumiv fizychnyh parametriv]. Computer-based learning systems: a collection of scientific papers [Kompiuterno-orientovni systemy navchannia: zbirnyk naukovych pratst]. 6, 260-268. [in Ukrainian]

7. Bardus, I. O., Yefimenko, Yu. O. (2011). Modeling of physical processes using the system of computer mathematics Maple [Modeliuvannia fizychnyh protsesiv za dopomohoiu systemy komp'iuternoi matematyky Maple]. Theory and practice of teaching physical, mathematical and technological disciplines: collection [Teoriia ta praktyka navchannia fizykomatematychnykh ta tekhnolohichnykh dystsyplin]. 38-46. [in Ukrainian]

8. Benker, H. (2013). Mathematische Optimierung mit Computeralgebrasystemen: Einführung für Ingenieure, Naturwissenschafter und Wirtschaftswissenschaftler unter Anwendung von MATHEMATICA, MAPLE, MATHCAD, MATLAB und EXCEL. Springer-Verlag. 499.

9. Musina, O., Putnik, P., Koubaa, M., Barba, F. J., Greiner, R., Granato, D., \& Roohinejad, S. (2017). Application of modern computer algebra systems in food formulations and development: a case study. Trends in Food Science \& Technology, 64, 48-59.

10. Solodov, A., \& Ochkov, V. (2005). Differential models: an introduction with Mathcad. Springer Science \& Business Media. 232.

11. Donnelly, D. P., \& Donnelly, D. P. (1992). MathCAD for introductory physics. Addison-Wesley. 386.

12. Dyadenchuk, A. F., Khalanchuk, L. V. (2020). Interdisciplinary links of physics and mathematics in the study of integral calculus [Mizhpredmetni zv'iazky fizyky i matematyky pry vyvchenni intehralnoho chyslennia]. Development of modern science and education: realities, quality problems, innovations: materials of the International scientific-practical Internet conference [Rozvytok suchasnoi nauky ta osvity: realii, problemy iakosti, innovatsii: materialy Mizhnarodnoi naukovopraktychnoi internet-konferencii]. 102-107. [in Ukrainian]

13. Dyadenchuk, A. F., Khalanchuk, L. V. (2020). Visualization of differential calculus problems in the preparation of engineering students [Vizualizatsiia zadach dyferentsialnoho chyslennia pry pidhotovtsi studentiv inzhenernych spetsialnostei]. Proceedings of the All-Ukrainian scientific-practical conference of applicants for higher education and young scientists "Classical and applied mathematical problems in research of applicants for higher education and young scientists: historical and modern aspects» [Materialy Vseukrainskoi naukovo-praktychnoi konferencii zdobuvachiv vyzchoi osvity i molodych vchenykh «Klasychni ta prykladni matematychni problemy u naukovych doslidzhenniach zdobuvachiv vyzchoi osvity i molodych vchenykh: istorychnyi ta suchasnyi aspekty» ]. 114-117. [in Ukrainian]

14. Shalaby, A. I., \& Zanganeh, S. E. (2000). Teaching fluid mechanics using MathCAD. ASEE Annual Conference Proceedings, $5,1$.

15. Sosnickaya, N., Morozov, M., Khalanchuk, L., Onyshchenko, H. (2019). Modelling the Electromagnetic Processes and Phenomena in Quantum-Sized Systems in the Course of Physical and Mathematical Support of Master's Programs for the "Electric Power Engineering, Electrical Engineering and Electromechanics Specialty. IEEE International Conference on Modern Electrical and Energy Systems (MEES). 402-405.

16. Radu, A., Grigore, I., Barna, V. (2020). Mathcad didactic tool for studying the elliptical oscillator. eLearning \& Software for Education, 2. Pp. 154-161.

17. Alekseev, R. Yu., Khobotova, A. Yu. (2016). Modeling of vibrational processes in Mathcad medium [Modelirovanie kolebatelnykh protsessov $\mathrm{v}$ srede Mathcad]. Science and perspectives [Nauka i perspektivy]. 2. URL: https://cyberleninka.ru/article/n/modelirovanie-kolebatelnyh-protsessov-v-srede-mathcad (access date: 16.08.2020). [in Russian]

18. Mathcad 2000 User's Guide (1999). Mathsoft, Inc., Cambridge, Massachusetts

19. Boyd, R. (1999). Tolerance Analysis of Electronic Circuits Using MATHCAD. Boca Raton: CRC Press, https://doi.org/10.1201/9781315215402

20. Kulik, H. M., Kushlyk-Divulska, O. I., Stepanenko, N. V., Yarema, N. P. (2016). Higher Mathematics: Integral calculus of a function of one variable. Differential equations: a textbook for students of technical specialties [Vyzcha matematyka: Intehralne chyslennia funktsii odniiei zminnoi. Dyferentsialni rivniannia: navchalnyi posibnyk dlia studentiv technichnykh spetsialnostei]. NTUU "KPI", Kiev 2016. 278. [in Ukrainian] 


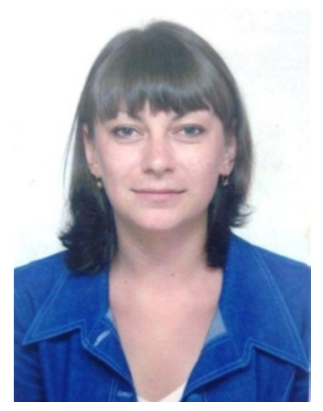

\section{Дяденчук Альона Федорівна,}

Кандидат технічних наук, старший викладач кафедри «Вища математика і фізика», Таврійський державний агротехнологічний університет імені Дмитра Моторного,

пр. Б. Хмельницького, 18, м. Мелітополь, Запорізька обл., 72312, Україна.

Тел. (066)8288519. E-mail: alena.dyadenchuk@tsatu.edu.ua

\section{Dyadenchuk Alena Fedorivna,}

Candidate of Technical Sciences, Senior Lecturer of the Department of Higher Mathematics and Physics,

Dmytro Motornyi Tavria State Agrotechnological University,

B. Khmelnytskoho Ave., 18, Melitopol, Zaporizhia Region, 72312, Ukraine.

Tel. (066)8288519. E-mail: alena.dyadenchuk@tsatu.edu.ua

ORCID: 0000-0002-6625-9985

Researcher ID: S-8700-2017

Scopus ID: 56081711200

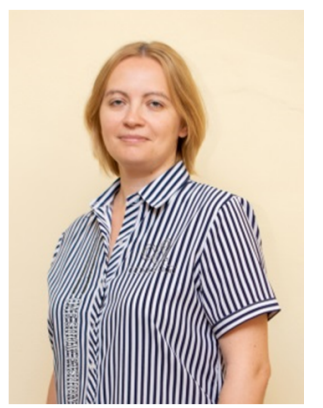

\section{Халанчук Лариса Вікторівна,}

Асистент кафедри «Вища математика і фізика»,

Таврійський державний агротехнологічний університет імені Дмитра Моторного,

пр. Б. Хмельницького, 18, м. Мелітополь, Запорізька обл., 72312, Україна.

Тел. (096)7798102 . E-mail: larysa.khalanchuk@tsatu.edu.ua

\section{Khalanchuk Larysa Viktorivna,}

Assistant of the Department of Higher Mathematics and Physics,,

Dmytro Motornyi Tavria State Agrotechnological University,

B. Khmelnytskoho Ave., 18, Melitopol, Zaporizhia Region, 72312, Ukraine.

Tel. (096)7798102 . E-mail: larysa.khalanchuk@tsatu.edu.ua

ORCID: 0000-0002-6055-6233

Scopus ID: 57211997783

\section{Citation (APA):}

Dydenchuk A. F., Khalanchuk L. V. (2020). Application of Mathcad environment in the general course of physics at preparation of experts of engineering specialties. Engineering and Educational Technologies, 8 (4), 40-50. doi: https://doi.org/10.30929/23079770.2020 .08 .04 .04

\section{Цитування (ДСТУ 8302:2015):}

Дяденчук А. Ф., Халанчук Л. В. Застосування середовища Mathcad у загальному курсі фізики при підготовці фрахівців інженерних спеціальностей / Інженерні та освітні технології. 2020. Т. 8. № 4. С. 40-50. doi: https://doi.org/10.30929/23079770.2020 .08 .04 .04

Обсяг статmi: сторінок - 11; умовних друк. аркушів - 1,593. 